\title{
CURSOS DE PEDAGOGIA E A FORMAÇÃO DO PROFESSOR DE CRECHE
}

\author{
PEDAGOGY COURSES AND TEACHER TRAINING IN NURSERY SCHOOL
}

\section{CURSOS DE PEDAGOGÍA Y FORMACIÓN DEL MAESTRO DE GUARDERIA}

\author{
Lilian de Assis Monteiro Lizardo \\ Universidade Presbiteriana Mackenzie - Brasil \\ Maria de Fátima Ramos de Andrade \\ Universidade Presbiteriana Mackenzie - Brasil
}

\begin{abstract}
Resumo: Este artigo resulta de pesquisa a respeito da formação inicial do professor de educação infantil que atuará na creche. Em que medida os cursos de Pedagogia instrumentalizam o professor no trabalho com bebês e crianças muito pequenas? Para responder a esta questão, optou-se por um estudo de abordagem qualitativa, estruturado em duas etapas: análise documental das ementas do curso de Pedagogia de duas universidades do estado de São Paulo (uma pública e outra particular) e da aplicação de questionários com alunos do último semestre. A partir da análise dos dados coletados, foi identificado que, nas ementas do curso de Pedagogia, há mais ênfase no ensino fundamental do que no ensino de conteúdos relacionados ao universo das crianças muito pequenas e de creche. Além disso, alunos de ambas as instituições afirmaram que na atuação do professor de educação infantil estão presentes tanto aspectos pedagógicos quanto aos relacionados ao cuidar.
\end{abstract}

Palavras-chave: Curso de Pedagogia. Formação inicial. Professor de creche.

Abstract: This article results from research about the initial training of the kindergarten teacher who will work in the day care center. To what extent do the Pedagogy courses equip the teacher in working with infants and very young children? In order to answer this question, we opted for a qualitative study, structured in two stages: documentary analysis of the menus of the Pedagogy course of two universities in the state of São Paulo (one public and another private) and the application of questionnaires with Students of the last semester. Based on the analysis of the collected data, it was identified that, in the menus of the Pedagogy course, there is more emphasis in elementary education than in the teaching of contents related to the universe of very young children and nursery school. In addition, students from both institutions stated that in the work of the teacher of children's education are present both pedagogical aspects and those related to care.

Keywords: Day care teacher. Initial training. Pedagogy course.

Resumen: Este artículo resulta de investigación acerca de la formación inicial del profesor de educación infantil que actuará en la guardería. ¿En qué medida los cursos de Pedagogía instrumentalizan al profesor en el trabajo con bebés y niños muy pequeños? Para responder a esta cuestión, se optó por un estudio de abordaje cualitativo, estructurado en dos etapas: análisis documental de los menús del curso de Pedagogía de dos universidades del estado de São Paulo (una 
pública y otra particular) y de la aplicación de cuestionarios con alumnos del último semestre. A partir del análisis de los datos recolectados, fue identificado que, en las menciones del curso de Pedagogía, hay más énfasis en la enseñanza fundamental que en la enseñanza de contenidos relacionados al universo de los niños muy pequeños y de guardería. Además, alumnos de ambas instituciones afirmaron que en la actuación del profesor de educación infantil están presentes tanto aspectos pedagógicos como a los relacionados al cuidar.

Palabras-clave: Curso de Pedagogía. Formación inicial. Profesor de guardería.

\section{Introdução}

Educação infantil tem sido uma temática muito discutida no campo educacional; muitos estudos têm mostrado a sua importância no processo de desenvolvimento e de educação da criança pequena. Cumpre lembrar que esse segmento escolar - educação infantil - divide-se em creche (atendimento de crianças até três anos) e pré-escola (atendimento de crianças de quatro e cinco anos). O presente trabalho de pesquisa se propôs a investigar a formação universitária do professor de educação infantil, tendo como foco o trabalho na creche. Partiu-se da seguinte questão: em que medida os cursos de Pedagogia apresentam temáticas/conteúdos direcionados ao exercício do magistério nos anos iniciais da educação infantil (creche)? A intenção foi analisar as ementas de cursos presenciais de licenciatura em Pedagogia, por responderem pela formação de professores da educação infantil, procurando obter um panorama do que está sendo proposto para a formação inicial do docente que atuará nesse segmento de ensino, procurando identificar ênfases que lhe estão sendo atribuídas e sua adequação às demandas profissionais. Nesse sentido, a intenção foi analisar como a formação de professores de creche é realizada dentro dos cursos de Pedagogia.

Para a realização desta pesquisa - de caráter qualitativo - inicialmente foi feito estudo documental (documentos oficiais e ementas de dois cursos de Pedagogia); na sequência, estudantes de Pedagogia responderam a questionários com perguntas fechadas e abertas. Neste artigo, apresentamos o referencial teórico que norteou o estudo e a análise dos dados que foram coletados. Por último, tecemos algumas considerações a respeito da temática proposta.

\section{Creches no Brasil: uma retomada histórica}

O que é creche? Por que foram criadas? Historicamente, a sua implantação esteve primeiramente associada ao atendimento da população carente; tinha o objetivo de ensinar às mães, preceitos de higiene, saúde e cuidados de seus filhos. 
A primeira creche de que temos registro, de acordo com Kuhlmann Junior (1991), está vinculada à fábrica de tecidos do Concordado e foi fundada em 1899. A partir desse início, foram surgindo creches vinculadas às fábricas e aos departamentos públicos. Kramer (2006) lembra que, em 1908, foi criada no Brasil a primeira creche popular dirigida aos filhos de operários de até dois anos de idade.

Com o processo de urbanização, houve um crescimento no número de vilas de operários que ficavam próximas às fábricas e indústrias. Como consequência, foram fundadas creches para atendimento do período de zero a dois anos. Algumas indústrias tinham salas de berçários para atender os filhos das operárias, os quais, depois dos três anos, dirigiam-se às escolas de educação infantil. De acordo com Kuhlmann Junior (2000),

[...] no Estado de São Paulo, desde dezembro de 1920, a legislação previa a instalação de escolas maternais, com a finalidade de prestar cuidados aos filhos de operários, preferencialmente, junto às fábricas que oferecessem locais e alimento para as crianças (p.08).

Nesse contexto, é possível compreender dois tipos de creches: uma para atender filhos de operários, mantida pela indústria, e outra de caráter filantrópico, para atender as crianças pobres e de risco social, mantida por igrejas, organizações não governamentais e senhoras da sociedade.

As creches que eram vinculadas à caridade estavam associadas a uma solução voltada para a "medicamentação a respeito da assistência aos infantes, o qual atribuía à família culpa pela situação de seus filhos" (OLIVEIRA, 2011, p. 92). As crianças sofriam riscos para sua saúde vinculados aos maus cuidados e à falta de higiene. Para ilustrar, Vieira (1988) lembra que as mães deixavam seus filhos com as criadeiras; quando eles adoeciam, eram submetidos a rituais com rezas e chás. Somente quando não melhoravam, as criadeiras chamavam as mães que, por sua vez, recorriam ao atendimento hospitalar.

Nas creches, as mães eram ensinadas a cuidar de seus filhos por meio de ações educativas de enfermeiras e médicos. Essa cultura higienista era para promover o Brasil enquanto uma nação, já que a "assistência, higienização e moralização compõem as facetas dessa intervenção sobre essa infância pobre” (ROCHA, 2005, p. 82).

Segundo Vieira (1988), foi a partir de 1940 que o Estado começou a investir nas instituições de cunho social, pois anteriormente as ações de atendimento à infância eram mantidas por outros órgãos não governamentais. Para o autor: 
Após 1940, além de intervir na questão das creches, criando dispositivos legais na CLT para sua instalação nos locais de trabalho, a cargo do empregador, o Estado procurou instituir, em nível do aparato técnicoburocrático, órgãos que centralizassem as assistências à mãe e à criança no Brasil. As creches, integrando uma política de proteção à maternidade e à infância, estiveram referidas às instituições da área da saúde e assistência social, criadas na década de 1940. (VIEIRA, 1988, p.04).

Concentradas nos centros urbanos, em 1946, havia vinte e nove creches localizadas em apenas nove estados brasileiros. Destas, "dezesseis estavam a cargo de associações particulares, quatro sob responsabilidade de congregações religiosas, três vinculadas à empresa e três à Legião Brasileira de Assistência - LBA"1 (VIEIRA, 1988, p. 12).

Nesse período, a creche tinha a finalidade de guardar as crianças, cuidando-as durante o dia, já que não possuíam condições de receber cuidados de seus pais (VIEIRA, 1988, p. 11). A creche era destinada às mães sozinhas, ou seja, aos filhos de mães solteiras, viúvas, largadas pelo companheiro, ou seja, àquelas mulheres que eram "forçadas a trabalhar" (ibid.).

Na década de 1970, as creches deixaram de ser vistas como "produtoras de carências, mas sim como compensadoras de faltas. As creches passam a se tornar um dispositivo para alimentar as crianças pobres" (VIEIRA, 1988, p. 5). Como estratégia para diminuir a desnutrição infantil, mediante a preocupação com o desenvolvimento e o organismo infantil, é garantido à criança ser bem alimentada: "Comer, brincar e dormir, consubstanciados em práticas de disciplinamento e constituição de um corpo saudável, robusto e forte" (ROCHA, 2005, p. 76) eram os eixos que articulavam o trabalho na educação infantil da época.

Em 1974, no Programa de Assistência ao Menor, mantido pela LBA, foi criado o Projeto Casulo, com objetivo de atender a um número elevado de crianças, com pouco investimento financeiro (KRAMER, 2006, p. 72). O Estado assumia uma parceria com instituições privadas, patrocinando materiais didáticos e de consumo, alimentação, equipamento, enquanto as instituições assumiam a responsabilidade pelo pagamento dos funcionários.

Esse projeto se caracterizava pelo atendimento de crianças de zero a seis anos, no período parcial ou integral (das $5 \mathrm{~h}$ às 20h), sem caráter escolarizante. O projeto propunha ações de nutrição e recreação por meio de cuidados voltados para a higiene, a médicos, dentistas e nutricionistas, com foco no desenvolvimento "biopsicossocial" (ibid.). Tal projeto

\footnotetext{
${ }^{1}$ LBA foi criada em 1942 por Darcy Vargas, primeira-dama do Brasil, com o objetivo de dar assistência à maternidade e à infância (RIZZINI, 1995, p. 291).
} 
foi sendo substituído por pré-escolas, a fim de amenizar os problemas de aprendizagem do então primeiro grau.

Com a homologação da Constituição Federal de 1988, a criança passou a ser um sujeito de direitos. O artigo 208 da referida lei determina a creche como seu direito educativo, além de ser um direito de todo trabalhador urbano e rural, como afirma o artigo 07, parágrafo XXV. "Daí a proposição de que as instituições de educação infantil precisariam transitar de um direito da família ou da mãe para se tornarem um direito da criança” (KUHLMANN JUNIOR, 2000, p. 12).

Nesse contexto histórico, as creches foram legitimadas como primeira etapa da educação da criança e transitaram da Secretaria do Bem-estar Social (assistência social) para serem regulamentadas e mantidas pela Secretaria de Educação. Com a homologação da Lei de Diretrizes e Bases - LDB 9394/96, foi regulamentado que a creche é a primeira etapa da educação infantil, atendendo crianças de zero a três anos, e estados e municípios teriam um prazo de dez anos para adequar-se à lei.

\section{A formação inicial do professor: o contexto da creche}

Quando se discute o conceito de formação docente, encontramos diferentes maneiras de conceber como ela poderia acontecer. A atividade docente, independentemente do segmento de ensino, é complexa, demanda tempo e é algo que se aprende.

As escolas normais representam o início das atividades referentes à formação inicial dos professores do ensino primário. A primeira Escola Normal brasileira foi criada em 1835, em Niterói, Rio de Janeiro, e era destinada ao público masculino (TANURI, 2000).

Para Garcia (1999), a formação inicial do professor cumpre três funções: a primeira é uma formação e treinamento do professor ligado à função que irá desempenhar. A segunda, voltada ao controle de certificação, que permite ao indivíduo exercer a profissão. A terceira é o diálogo entre duas incumbências, a de ser um agente transformador do sistema educativo e a de "contribuir para a socialização e reprodução da cultura dominante" (p. 77).

Garcia (1999) entende que a formação pode possuir a função social "de transmissão e saberes, de saber-fazer, e do saber ser que exerce em benefício do sistema socioeconômico ou da cultura dominante" (p. 19). Também pode ser "um processo de desenvolvimento e estruturação da pessoa que se realiza com o duplo efeito de uma maturação interna e de possibilidades da aprendizagem, de experiências do sujeito" (GARCIA, op. cit.). É também 
possível pensar na formação enquanto instituição, que se refere à "estrutura organizacional que planifica e desenvolve as atividades de formação" (GARCIA, op. cit.).

Sendo assim, compreende-se que a formação inicial é o princípio da "socialização profissional e da assunção de princípios e regras práticas" da profissão (IMBERNÓN, 2002, p. 60). Ela permite que o indivíduo aprenda os valores da profissão, construa competências válidas para exercer seu papel, problematizando sua prática e transformando-a de forma a ressignificar o seu papel social.

Quando Freire (1996) diz que somos seres inconclusos, compreende-se que estamos em constante aprendizado, em formação contínua, de acordo com os conhecimentos teóricos e experienciais que vivemos. Não existe um término no ato de aprender, pois as informações não possuem uma totalidade: sempre há algo a mais para conhecer. Logo, não existe um fim na formação docente; sempre há algo novo ou que ainda precisa ser melhor aperfeiçoado. "Quem forma se forma e re-forma ao formar e quem é formado forma-se e forma ao ser formado" (FREIRE, 1996, p. 23), ou seja, na medida em que o indivíduo é formado, ele contribui para a formação do outro, podendo ser aluno, professor ou até mesmo a comunidade. Por isso Freire (1996) diz que "não há docência sem discência" (p.21), não há ensino sem aprendizagem. Dessa forma, entende-se que não há professor sem aluno; ou não há professor sem a sua própria aprendizagem docente.

Desde que nascemos, estamos em constante aprendizado, por isso a necessidade de olhar para o bebê como um sujeito com competência, que precisa de desafios que colaborem cada vez mais o seu desenvolvimento. Tais desafios devem ser ofertados por professores que tenham um olhar diferente para a aprendizagem da criança. Historicamente, o papel do professor de educação infantil é

[...] um campo complexo e multifacetado que exige reflexões sobre as marcas culturais de um profissional de nível inferior que estão entranhadas entre nós. Esse fazer, com a conotação de 'cuidar', passou a ser 'atividade de mulher', o que exige pouca qualificação. (KRAMER, 2005, p.125).

O papel das professoras de crianças muito pequenas exige que desempenhem diferentes tarefas voltadas para o cuidado (higiene, limpeza e saúde) e para a educação (aprendizagem, desenvolvimento). A dependência da criança demonstra a sua vulnerabilidade. Portanto,

[...] a globalidade da educação da criança pequena requer das educadoras um alargamento de responsabilidades pelo funcionamento da criança. Assim, a educadora da infância desempenha uma enorme diversidade de tarefas e tem 
um papel abrangente com fronteiras pouco definidas. (FORMOSINHO, 2005, p. 138)

Para Formosinho (2005), a profissionalidade é a ação do professor junto às crianças, suas famílias e comunidade, que se utiliza de seus "conhecimentos, competências e sentimentos, assumindo a dimensão moral da profissão". (FORMOSINHO, 2005, p. 133).

A profissionalidade envolve a prática docente e a aprendizagem dos conhecimentos tácitos nas diferentes áreas do currículo educacional, que deveria ser contemplada de acordo com as diferentes etapas que o professor irá exercer sua profissão, além de contribuir para a consolidação da identidade do professor.

\section{A análise dos dados: a formação do professor de creche}

A pesquisa foi realizada em duas universidades, que chamaremos de A e B: uma pública, e outra privada. Na Universidade A, encontramos 41 disciplinas. Ao analisarmos as ementas, identificamos duas que utilizam o termo "educação infantil" em seus títulos. Além disso, encontramos outras duas que possuem temáticas e/ou referências bibliográficas direcionadas a esse segmento de ensino. Nas ementas analisadas, não localizamos a palavra "creche". Apenas identificamos duas disciplinas continham em suas bibliografias, o Referencial Curricular de Nacional da Educação Infantil (RCNEI). Outro dado observado, em algumas disciplinas, foi que a bibliografia básica não dialogava com a ementa. Por exemplo, na disciplina intitulada "Jogos e brincadeiras", não foram encontrados textos que pudessem servir de referência para a temática.

Com relação às disciplinas de metodologia, o conteúdo era predominantemente do ensino fundamental. Nas disciplinas relacionadas à alfabetização, apesar do termo "educação infantil" ser citado na ementa, não identificamos no referencial bibliográfico textos direcionados esse universo.

Ao localizarmos, nas ementas, os conteúdos descritos no RCNEI no eixo "Natureza e sociedade", não conseguimos identificar se são trabalhados temas relacionados ao segmento da creche. Novamente, o que identificamos foi uma predominância do ensino fundamental. Na ementa da disciplina que trata de conteúdos da matemática, verificamos a expressão “educação infantil” e, na bibliografia, o RCNEI foi citado. Não conseguimos constatar se o trabalho estava direcionado para creches. 
Resumidamente, a palavra "creche", nas ementas analisadas, não foi referenciada. O termo "educação infantil" foi citado sete vezes e "ensino fundamental", dez vezes. O que está escrito nas ementas não foi suficiente para que se soubesse se o uso do termo "educação infantil” englobou os conteúdos relacionados ao contexto da creche.

A Universidade B disponibilizou apenas a grade curricular do curso de Pedagogia. Com a leitura da grade curricular foi possível perceber que, das 56 disciplinas ofertadas, apenas uma tem em seu título o termo "educação infantill".

$\mathrm{Na}$ tentativa conhecer um pouco mais o que os alunos aprenderam, na formação inicial, de conteúdos relacionados à atuação na creche, questionários foram aplicados em ambas as instituições.

\section{Universidade A: a realização dos questionários}

A aplicação dos questionários foi realizada com 59 alunos do último semestre de Pedagogia. Na primeira parte, procuramos traçar o perfil dos entrevistados.

- $\quad 96,6 \%$ dos estudantes identificaram-se como pertencentes ao gênero feminino.

- $47,4 \%$ dos estudantes estão entre a faixa etária de 20 a 25 anos.

- 3 alunos fizeram Magistério, na modalidade Técnico; e dois já exercem à docência.

- $81,3 \%$ dos estudantes atuam como auxiliares de classe.

No segundo momento de aplicação dos questionários, os estudantes responderam a questões fechadas e abertas acerca da formação que receberam com relação à atuação no segmento-creche. Quando indagados a respeito do local da realização dos estágios obrigatórios, prioritariamente, eles responderam que foram realizados na pré-escola.

Como sabemos, ao estagiar, o aluno da graduação tem a oportunidade de fazer relações entre a teoria que está sendo ensinada na universidade e a prática desenvolvida na escola, ou seja, é um espaço importante para a construção do conhecimento prático. Analisando os dados, percebemos que os alunos tiveram menos oportunidades para acompanhar ações desenvolvidas nas creches. Esse aspecto provavelmente irá interferir na construção do conhecimento prático tão necessário para uma atuação mais qualificada.

Após responderem às questões fechadas, os alunos responderam a seis questões abertas. Na primeira, perguntamos quais as contribuições do curso para o exercício profissional na creche; a maioria afirmou que contribuiu para o exercício da docência na creche. As falas a seguir ilustram essa afirmação: 
Sim, para mim contribuiu, pois pude conhecer mais este ambiente escolar, como funciona, como as crianças são tratadas e como uma pedagoga deve cuidar de certas situações. (ESTUDANTE A-02)

Com o curso de Pedagogia obtive conhecimentos teóricos que me auxiliaram no trabalho com as crianças; exemplo disso foi no desenvolvimento das crianças nessa idade com que trabalho. (ESTUDANTE A-03)

Sim, mostrando que cada criança é de um jeito e como trabalhar projetos. Projeto de identidade para conhecer melhor as crianças. (ESTUDANTE A11)

Sim, o curso contribuiu para que eu compreendesse que todas as nossas ações devem ser pensadas e refletidas com um objetivo/propósito, como uma simples troca de fralda, este pode ser um rico momento de aprendizagem para o aluno. (ESTUDANTE A-17)

Contudo, onze alunos relataram que o curso não contribuiu com conhecimentos específicos para o exercício nesse segmento. Por exemplo:

Sim, somente para a creche mas para todos os ciclos, claro que na creche não tem muito a parte da Pedagogia, só a parte de cuidados e desfralde, onde na faculdade não tive muito essa aprendizagem. (ESTUDANTE A-01)

Eu não me sinto preparada para o trabalho em creche pedagogicamente, pode ser que me saia bem por ser mãe. As aulas que tratavam dessas questões foram bastante vagas. (ESTUDANTE A-11)

Acredito que nossa formação inicial não aborde todos os conteúdos, ou esgote-os de maneira que sintamos segurança para atuarmos principalmente nas creches e pré-escolas. Pois trabalhar com crianças de 0 a 3 anos e 4 e 5 anos requer conhecimentos científicos específicos. (ESTUDANTE A-23)

A estudante A-01 relatou que o curso contribuiu para o conhecimento de diferentes modalidades, todavia, na sua compreensão, para atuação na creche não é necessário conhecimento pedagógico. Outra resposta semelhante foi dada pelo aluno A-09, que disse: "Por ser mãe, talvez seu trabalho na creche poderia ser bom". Percebe-se, com essas falas, ainda uma visão assistencialista de educação.

Em relação aos estágios, a maioria dos alunos tiveram experiência na creche, quando se tratava da Educação Infantil. Mas quando faz referência aos outros estágios, cerca de 37 alunos têm preferência por realizar no Ensino Fundamental I.

Quando os alunos foram questionados sobre quais conteúdos foram evidentes nesses estágios, alguns descreveram o conteúdo, outros abordaram algumas atividades.

Foram as rodas de leitura, pois as crianças sempre prestaram atenção. As atividades de coordenação motora foram bem significativas. $\mathrm{O}$ que marcou 
foi a proposta investigativa das professoras, ambas sempre incentivavam as crianças a refletirem sobre suas ações. (ESTUDANTE A-05)

Números, exemplificando. Cores e formas. (ESTUDANTE A-08)

Corpo e movimento. Desenho livre. (ESTUDANTE A-15)

Para dois alunos a brincadeira não possui relação com conteúdo, já que disseram o seguinte:

Fiz em creche e lá quase não tem conteúdos, mais parque, brinquedos, etc. (ESTUDANTE A-01)

Na verdade, em relação aos estágios em educação infantil não tive grandes experiências. Durante o período de estágio que fiquei na escola, não havia atividades direcionadas, as crianças ficaram a maior parte do tempo brincando. (ESTUDANTE A-28)

Na sequência, os estudantes responderam questões a partir de situações problemas que envolviam a função do professor de creche. Quatro alunos, quando responderam à questão "Como você definiria a função do professor de creche (crianças até três anos)?", disseram que o professor é um estimulador do desenvolvimento infantil. Provavelmente esse pensamento torne a docência em creche simplista, podendo qualquer profissional atuar no segmento, mesmo sem formação específica. Além disso, a ação desenvolvida é vista como algo que contribui para o que virá. Nesse sentido, corre-se o risco de a criança que temos não ser olhada, pois projetamos o que gostaríamos que ela fosse.

Nesse período a criança precisa de estímulos e ser sensibilizada para futuras aprendizagens, essa é a função do professor com essa faixa etária. (ESTUDANTE A-01)

Fundamental, pois os processos educativos e estimulação começam já desde bebê, um processo de estimulação bem feito teremos alunos mais curiosos a aprender. (ESTUDANTE A-16)

É de extrema importância, pois a primeira infância é o momento do primeiro contato com o aprendiz, além de estimular o convívio entre as crianças socialmente. (ESTUDANTE A-21)

Outras respostas apontaram a relação entre o educar e o cuidar na função do professor.

Cerca de 23 alunos consideraram aspectos que valorizam a base da educação infantil: educar e cuidar. As principais foram:

O professor deverá ter a função de ensinar, também de cuidar e proporcionar às crianças uma aprendizagem mais prática. (ESTUDANTE A-06) 
O professor de creche tem a função de cuidar e formar essa criança em todos os seus aspectos, cognitivo, motor, emocional e social. (ESTUDANTE A09)

Professor deve atender às necessidades das crianças, cuidar e fazer planejamentos relevantes para cada idade e etapa do desenvolvimento da criança. (ESTUDANTE A-13)

O professor na creche deve atrelar as funções: educar/cuidar, pois os anos iniciais necessitam de cuidados físicos que caminharam juntos com o processo de aprendizagem da criança. O professor da creche deve ter um ponto de equilíbrio entre essas duas funções. (ESTUDANTE A-20)

O educador deve ter um olhar atento às necessidades das crianças. Deve buscar compreender o processo de pensamento e resolver os conflitos através de conversas e afeto. O educador deve promover um ambiente acolhedor, investigativo e curioso. (ESTUDANTE A-57)

Algumas respostas dizem que a função do professor está ligada com características de sua personalidade, evidenciando questões voltadas para a afetividade, atenção, confiança, como podemos perceber nas seguintes falas:

Principalmente, o professor tem que ter uma postura ética, conscientizada nas ações, um profissional que não seja cara fechada e sim uma pessoa que venha estar passando confiança, que virá ser um profissional que irá fazer o seu melhor. (ESTUDANTE A-02)

Atencioso, comunicativo, expressivo. (ESTUDANTE A-15)

Essencial, pois nesse início de escolaridade a criança se sente insegura. $\mathrm{O}$ professor deve passar segurança para a criança, de forma que ela se interesse e goste de ir para a escola aprender novas vivências. (ESTUDANTE A-19)

Professor com perfil dinâmico, afetivo, inovador e criativo. (ESTUDANTE A-49)

O professor de creche é um professor observador, calmo, criativo e dinâmico. O professor de creche tem que ser completo, pois lida com crianças em desenvolvimento. (ESTUDANTE A-59)

E, ainda, há as respostas que relatam que o professor de creche, apesar de ter uma função pouco definida, é abrangente:

Um professor polivalente e que contribui de forma significativa para seu aprendizado e desenvolvimento (ESTUDANTE A-03) 
A função é trazer e mostrar para as crianças, suas capacidades e habilidades, mesmo sendo bem pequenas. Trabalhar a parte lúdica. Proporcionar situações de reconhecimento do Eu e o próximo. (ESTUDANTE A-05)

Educador, aquele que desenvolve as primeiras aprendizagens do conhecimento científico através da brincadeira, respeitando o estágio da criança. (ESTUDANTE A-12)

O professor de creche tem uma função de instigar e desenvolver a autonomia e identidade da criança até três anos, pois estão começando a se reconhecer como seres no mundo. Isso é muito importante. (ESTUDANTE A-14)

Uma função muito importante, pois ele (professor) estará formando o sujeito para o mundo, então suas atitudes são de suma importância. Seu jeito de agir frente as crianças, as atividades que serão feitas. (ESTUDANTE A-18)

Professor de creche, acima tudo tem que ter afeto, carinho, respeito, pois ali ele será como pai e mãe, daqueles pequenos, paciente, compreensivo, é um educador e um cuidador ao mesmo tempo. Saber lidar com as famílias em sua diversidade, acolher sempre a criança. $\mathrm{O}$ carinho é essencial e isso sem pensar a qual família pertence, olhar a criança em suas particularidades e individualidades. (ESTUDANTE A-38)

É possível afirmar que, para esses estudantes, não há uma visão única e sim a difusão de diferentes vertentes, que contribuem para o trabalho na educação infantil.

\section{Universidade B: a aplicação dos questionários}

A aplicação do questionário foi realizada com sessenta alunos do último semestre de Pedagogia. Na primeira parte do questionário, procuramos traçar o perfil dos entrevistados.

- Os alunos se identificaram como 58 do gênero feminino e dois do masculino.

- $48,3 \%$ estão entre a faixa etária de 20 a 25 anos.

- Um aluno fez Magistério, na modalidade Técnico.

- $26,7 \%$ não possuem vínculo empregatício com o setor educacional.

- $50 \%$ dos entrevistados atuam como auxiliares de classe.

Num segundo momento, solicitamos aos alunos do último semestre do curso de Pedagogia que respondessem a um questionário com questões fechadas e abertas. A intenção foi identificar se os alunos estudaram conteúdos relacionados ao segmento da creche. Quando indagados a respeito do local da realização dos estágios obrigatórios, prioritariamente, eles foram realizados na pré-escola. Resumidamente, responderam: 25\% na creche; $38 \%$ na préescola; $29 \%$ tanto na creche quanto na pré-escola; e $8 \%$ não responderam. Quando questionados a respeito dos demais estágios, os alunos afirmaram, em sua maioria, que foram realizados no ensino fundamental. 
Ao serem indagados se o curso de Pedagogia contribuiu para o exercício profissional de creche, a maioria afirmou que sim, o curso contribuiu. Contudo, quando analisamos o que foi dito, percebemos que nem todos especificaram em suas respostas aspectos relacionados às contribuições na formação do profissional que atuará em creches. Eles afirmaram:

Sim, pois aprendemos na LDB como trabalhar, o que trabalhar e muita coisa sobre o comportamento e fases. (ESTUDANTE B-58)

Estudar me tornou uma pessoa melhor, sendo assim, posso contribuir com conhecimento e desenvolvimento como professora. (ESTUDANTE B-38)

Contribui para exercer tudo o que aprendi na teoria, podendo assim adquirir experiência e conhecimento para meu currículo e vida. (ESTUDANTE B40)

Sim, dando oportunidade de vivenciar se a teoria está de acordo com a prática. (ESTUDANTE B-34)

Pela análise das outras respostas afirmativas, percebemos que seis alunos concluíram que o estágio foi um momento importante para o aprendizado. Eles mencionaram como a teoria trabalhada na universidade estava presente na prática observada. Contudo, não conseguiram expressar, em suas falas, que teoria e/ou que prática estava sendo observada e relacionada.

As falas a seguir ilustram essa afirmação:

Sim, através da observação do estágio deu para avaliar o trabalho do professor em sala de aula, as atividades desenvolvidas que vão além das brincadeiras, ajudando na aprendizagem das crianças. (ESTUDANTE B-30) Sim, pois mostrou de forma prática e através do estágio o perfil do educador de creche, que deve ser espontâneo, criativo, ágil e muito mais. (ESTUDANTE B-03)

Sim, acredito que o curso tenha me dado bagagem cultural e conhecimentos teóricos e práticos para atuar na área. E pude observar que, nos estágios tive a oportunidade de ver na prática os conteúdos trabalhados no curso. (ESTUDANTE B-26)

Sim, por meio de estágios, adquiri o conhecimento necessário. Na faculdade tenho a teoria, com o estágio, coloco em prática. (ESTUDANTE B-01)

Sim, por ter prática nos estágios, assim fazendo um bom trabalho. (ESTUDANTE B-04)

Para outros, o curso não contribuiu. Constatamos que algumas respostas estavam relacionadas ao fato de não terem feitos seus estágios nesse segmento. Isso foi observado nas falas: 
Não tenho nenhuma experiência em creches e berçários. (ESTUDANTE B07)

Não estagiei em creche. (ESTUDANTE B-22)

Não, pois o curso é muito teórico, envolvendo quase nada a prática, essa sim seria a principal que deveríamos ter. (ESTUDANTE B-47)

Não, pois tivemos pouca prática e muita teoria. (ESTUDANTE B-48)

O curso de Pedagogia contribui "superficialmente" para o exercício da docência em creche, pois os conteúdos trabalhados em sala de aula foram mais na teoria. Ao meu ver, deveria ter mais estudo de causas. (ESTUDANTE B-56)

Parece-nos que um aspecto relevante é a maneira como os estágios estão estruturados no curso. Mesmo que a Universidade B oferecesse um currículo com conteúdos direcionados ao segmento da creche, sem o diálogo entre a teoria e a prática, muitas vezes propiciado pelos estágios, os alunos não conseguiram expressar mais especificamente o que contribuiu para a formação do professor que nela atuará.

Cumpre lembrar que na Resolução no 02/2015 que define as Diretrizes Curriculares Nacionais do curso de Pedagogia está expresso que a formação profissional deveria reconhecer a "especificidade do trabalho docente, que conduz a práxis como expressão da articulação entre teoria e prática e à exigência de que se leve em conta a realidade dos ambientes das instituições educativas da educação básica e da profissão" (BRASIL, 2015,

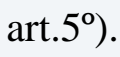

Nesta perspectiva, Mizukami (1986) lembra que as teorias não se limitam a si mesmas: elas foram criadas para contextualizar um determinado fenômeno. A partir de determinada realidade, fornecerão subsídios para serem aceitas ou não, "instalando-se um processo de discussão permanente entre teoria e prática" (p. 107). Logo, as atividades de estágio, quando bem planejadas, são fundamentais no processo de formação inicial.

Na sequência, considerando as experiências realizadas na educação infantil nos estágios, pedimos que os alunos mencionassem os conteúdos trabalhados pelo professor regente, que foram mais significativos para a sua formação. A maioria apontou conteúdos relacionados ao contexto da educação infantil, lembrando que, para muitos, a palavra "conteúdo" estava relacionada com os procedimentos metodológicos realizados. Exemplificando: 
Atividades usando o corpo para estimular a coordenação motora. Atividades com música para desenvolver oralidade. (ESTUDANTE B-01)

Pouco participei dos momentos de conteúdo trabalhados em sala de aula, até mesmo porque estagiei em uma creche Waldorf e o que é priorizado é brincar sempre com a supervisão e olhar acolhedor das professoras. (ESTUDANTE B-17)

Os conteúdos foram roda de conversa, contação de histórias, desenhos para se trabalhar a coordenação motora, conhecimento de cores, brincadeira, filmes de histórias infantis. (ESTUDANTE B-22)

Os conteúdos que trabalham com os conceitos do cotidiano, fazendo com que a aprendizagem seja significativa para a criança, como trabalhos com alimentos que a criança tem acesso. (ESTUDANTE B-35)

Bom, a importância de manter sempre uma rotina e seus horários e a contação das historinhas. Ex.: quando a professora contava a historinha, os alunos se sentavam em roda e ficavam todos empolgados com o final. (ESTUDANTE B-37)

Nove alunos não responderam à questão proposta e nove afirmaram que não aprenderam nada que tenha sido significativo com a realização do estágio. Os alunos afirmaram:

Não, pois tivemos pouca prática e muita teoria. (ESTUDANTE B-46)

Na minha opinião, em nada, pois quase não tivemos aula sobre creche, afinal não tivemos nenhuma aula, nenhum professor que falasse sobre isso. (ESTUDANTE B-49)

Não contribui tanto, pois conciliar trabalho, estudo e estágio é irreal. A proposta de estagiar poucas horas diárias sem que haja uma rotina para entender a rotina das crianças não facilita compreender e viver melhor 0 ambiente escolar. (ESTUDANTE B-17).

Para Garcia (1999), tanto a formação inicial quanto a continuada deveriam partir de uma reflexão epistemológica da prática, de forma que o ato de aprender a ensinar possa vir integrado pela teoria e pela prática num currículo voltado para a ação. Dessa forma, podemos compreender que a teoria e a prática estão integradas, mas nem sempre é visível aos olhos de quem está estagiando. Por isso, Vaillant e Marcelo (2012) diz que é necessário um roteiro de observação para nortear os estágios, pois os alunos aprendem melhor quando conhecem "o que" e "para que" fazem determinadas atividades. Nesta perspectiva,

A formação inicial deveria planejar adequadamente os estágios para que eles se transformassem em uma ocasião para aprender, com a existência de um currículo específico inserido no currículo oficial acadêmico, que 
contemplasse a necessidade de atender as práticas como componente de formação profissional. (VAILLANT; MARCELO, 2012, p. 78)

Com relação aos conteúdos, foram observados, na fala dos alunos, que no estágio em educação infantil, os jogos e brincadeiras prevaleceram, juntamente com o trabalho com música, linguagem oral e escrita. Quando foi falado de matemática, das seis pessoas que disseram ter observado o trabalho com a contagem, apenas uma referiu-se especificamente à forma como a professora trabalhou. Como foi relatado:

Durante o estágio, a professora trabalhou com os alunos diversos conteúdos, mas coisas diárias como dizer qual era o dia, o número de alunos, trabalhar as letras com o nome de cada um, práticas as quais eu pretendo adicionar em minha metodologia. (ESTUDANTE B-28)

Assuntos referentes às especificidades das disciplinas de ciências, história e geografia foram pouco evidenciados. Apenas nas falas abaixo algumas ações relatadas. São elas:

Os conteúdos mais significativos foram: descoberta das partes do corpo, formas geométricas, literatura, gincanas, animais, natureza (cuidados com os espaços) e principalmente descobertas sobre o local onde mora. (ESTUDANTE B-29)

Natureza e sociedade. As crianças podiam usufruir do pomar da escola, realizando diversas experiências musicais; as crianças trabalhavam com músicas de outros países, trazendo suas culturas para o nosso pais. (ESTUDANTE B-45)

Natureza e sociedade: o professor levava as crianças para estudo do meio. Achava importante, pois acredito que o aluno aprende melhor vivenciando. (ESTUDANTE B-48).

Quando indagados a respeito da função do professor que atua no segmento da creche, dos sessenta alunos, dezesseis não responderam a essa questão. A maioria - doze alunos afirmou que a função tem relação com o cuidar e educar. Em contrapartida, nove afirmaram que a função é basicamente o cuidar. As respostas ilustram essa afirmação:

Uma função que nos requer basicamente atenção e cuidados. (ESTUDANTE B-04).

Em primeiro lugar o professor precisa amar cuidar, ser paciente com tudo. Deve ser criativo, alegre e ter amor, carinho por sua profissão. (ESTUDANTE B-46).

O professor de creche é professor assim como os outros. Sua função é ensinar, porém é o ensinar mais voltado para o brincar e o cuidar. (ESTUDANTE B-50). 
Alguém que cuida na produção da evolução da criança. (ESTUDANTE B52)

O professor da creche é incumbido de cuidar dos educandos, visando sua segurança e a construção de sua própria autonomia. (ESTUDANTE B-56).

Definiria como algo rotineiro. A criança precisa ter rotina, hora para tudo e suas necessidades supridas, higiene e estimulação. (ESTUDANTE B-58).

O professor de educação infantil tem que ser um profissional comprometido e se envolver no processo de ensino aprendizagem, e acima de tudo tem que ser observador e cuidadoso, porque as crianças até três anos de idade necessitam de cuidado e carinho. (ESTUDANTE B-60).

Outros afirmaram que a função é mediar. Contudo não especificaram o que será mediado. Diante das respostas dadas e considerando que são discentes do último semestre, constatamos que os alunos estão terminando a graduação com a visão de que ser professor de creche pressupõe ações relacionadas basicamente ao cuidar. Como sabemos, essa concepção de cuidado está intrinsicamente ligada com os processos históricos de como a creche foi constituída, bem como a função dos seus profissionais. As professoras apenas assumiram a função de cuidadoras das crianças.

Com relação às questões "O que o professor precisa saber para trabalhar em berçários? Quais os conteúdos a serem trabalhados com os bebês?", os alunos afirmaram que o profissional de educação infantil precisa conhecer conteúdos relacionados ao desenvolvimento humano e à construção da autonomia. Entre eles, os mais destacados foram:

Para berçário é necessário um cuidado mais atento. Essa idade necessita de muita atenção do professor; cuidados básicos são de extrema importância. Coordenação motora; exercícios estimulando a oralidade. (ESTUDANTE B01)

Precisa ser didático e criativo; conteúdos que buscam autonomia com bebês. (ESTUDANTE B-23)

Ser paciente, tomar muito cuidado, ter disposição, coordenação motora grossa, ler livros, pinturas, massinhas. (ESTUDANTE B-37)

Que os cuidados precisam ser maiores e que se pode trabalhar conteúdos que desenvolvam a coordenação motora. Natureza e sociedade, números, língua oral. Trabalhar oralidade, movimentos corporais. (ESTUDANTE B-41)

Além da Pedagogia, o professor precisa saber desenvolver projetos, trabalhar passo a passo o desenvolvimento da criança, aplicando cuidados higiênicos, alimentação, observações no físico da criança. (ESTUDANTE B-42)

Desenvolvimento do bebê, desenvolvimento da linguagem e coordenação motora (ESTUDANTE B-47) 
Quinze, dentre sessenta alunos, não responderam a essa questão; três escreveram uma resposta que não correspondia ao proposto:

Não tenho experiência. (ESTUDANTE B-04)

Nunca trabalhei em berçários, não tenho conhecimento sobre isso. (ESTUDANTE B-19)

Não sei, não estagiei em berçários. (ESTUDANTE B-22)

Foi possível compreender que, para esses alunos, o conhecimento do conteúdo advém primeiramente da experiência do professor. Além disso, ao responderem a essa questão, alguns apontaram que tanto os conhecimentos específicos quanto os pedagógicos são necessários para uma prática qualificada. Exemplificando, teríamos:

Deve saber sobre os estímulos e em qual fase se encontra o bebê, para que possa utilizar outros métodos pertinentes. (ESTUDANTE B-09).

Trocar crianças, entender suas singularidades e pluralidades, trabalhar o tripé de forma ampla e complexa, porém de forma diversificada; os conteúdos a serem trabalhados com os bebês são prioritariamente o tripé. (ESTUDANTE B-14)

Paciência, criatividade, alegria e gostar do que faz. Rotina, equilíbrio, agilidade, coordenação motora e higiene. (ESTUDANTE B-18)

Precisa ter cuidados com a higiene, prestar atenção nas rotinas, coordenação motora, trabalhar com eles muitas músicas. (ESTUDANTE B-20).

O professor precisa saber que além dos cuidados essenciais, os bebês necessitam realizar atividades que estimulem seu desenvolvimento e aprendizagem, como, por exemplo, seguir com os olhos a luz da lanterna ou brincadeiras com músicas. (ESTUDANTE B-54).

Shulman (2014) diz que o professor precisa de diferentes conhecimentos. Entre eles está o conhecimento do conteúdo, que é o meio especial de compreensão profissional do ser professor, na integração de estratégias pedagógicas com o conteúdo específico.

Houve apenas uma resposta sugerindo que o curso não possui conteúdos que se aprofundem no conhecimento dos bebês, exceto a disciplina psicologia, como o estudante diz: "Na verdade, na Pedagogia não tem nenhuma matéria que trabalha a questão dos bebês. Só podemos citar a psicologia, em que se trabalha os primeiros processos dos bebês" (ESTUDANTE B-16). 
$\mathrm{Na}$ parte final do questionário, trabalhamos com duas situações-problema que poderiam ocorrer na sala de educação infantil. Na primeira, perguntávamos como o estudante de Pedagogia criaria estratégias para lidar com a questão de mordidas e arranhões constantes em uma determinada sala de berçário. A maioria apontou, como estratégia de ação, ao se depararem com a situação das mordidas em sala de aula, a construção de um diálogo mais próximo com as famílias. Para os alunos, a mordida acontece numa fase e, como tal, precisa ser trabalhada com a colaboração todos. Eles disseram:

Uma reunião para os pais para esclarecer as dúvidas frequentes, deixando claro que nessa idade eles usam esse tipo de atitude como defesa, disputa de brinquedo. Um trabalho junto com a família da criança. (ESTUDANTE B10)

Conversaria com os pais para explicar que nessa idade..., então convidaria os pais para participar um dia ou período com seus filhos e colegas para compreender um pouco mais das crianças fora do ambiente escolar. (ESTUDANTE B-17)

Fazer uma reunião com os pais, informando que os cuidados são tomados, sim, mas as crianças não estão livres de se morderem, que é a fase delas. (ESTUDANTE B-21)

Explicar aos pais a importância e significado da fase oral da criança. Propor atividades com brinquedos que eles possam morder, como bolinhas de borracha e mordedores. (ESTUDANTE B-26)

Sim, os pais pedem para observar mais, porém outros entendem. (ESTUDANTE B-23)

Poderia ser marcada uma reunião com os pais, explicando que a mordida faz parte das vivências das crianças menores e que é trabalhado isso com eles no dia a dia para que haja uma diminuição. (ESTUDANTE B-29)

Convoco os pais para uma reunião para ressaltar que a crianças nessa fase estão se autodescobrindo e que é normal que isso aconteça entre eles. Que ficamos atentos e que iremos mediar as crianças com conversas. (ESTUDANTE B-45)

Em contrapartida, alguns alunos responderam que não deixariam as crianças ociosas, ou seja, modificariam a prática e incluiriam mais atividades para ocupar o tempo não programado. Isso ficou explícito nas falas:

Criar mais "momentos" que possibilitem maior interação entre os alunos, momentos que sejam prazerosos, não os deixando ociosos. (ESTUDANTE B-09)

Cortar as unhas e deixar em espaços maiores. (ESTUDANTE B-25) 
Nunca os deixar (sem uma atividade), estar mais próxima o possível para intervir em uma possível ocorrência e sempre conversar, orientando que o carinho é o que o amigo tem que receber. (ESTUDANTE B-27)

O principal é dizer não para a criança e sempre que acontecer repetir a fala, de maneira firme, mas sutil. Porém, deve ser identificado se: os dentinhos estão crescendo; se a criança sente fome. (ESTUDANTE B-32)

Não os deixando com tempo livre, sempre corrigindo quando ocorrer o fato. (ESTUDANTE B-37)

Desenvolver atividades em que os bebês foquem a atenção em algo que não seja os amigos. (ESTUDANTE B-47)

Estar observando quando ocorrem as mordidas e quando se unham e sempre trocar de brincadeira ou atividade (ao menos a cada 30 minutos). (ESTUDANTE B-54)

Com relação ao conteúdo das respostas dadas, alguns alunos fizeram referência ao campo da psicologia, ao retratarem a fase oral da criança e/ou a fase do desenvolvimento como sendo algo a ser considerado nas mordidas.

Conversar com as famílias, explicando que é uma fase em que eles se encontram, mostrando para elas que é um fato normal para a idade. (ESTUDANTE B-30)

Conversar, mostrar que isso é da criança; isso ocorre no seu desenvolvimento. (ESTUDANTE B-34)

É necessário que haja o entendimento de que são crianças pequenas; esses hábitos são normais em sua fase. Utilizar o lúdico, deixar essas crianças brincarem juntas e não separar, manter um diálogo por mais que não entendam muito bem. (ESTUDANTE B-50)

A criança, nesta fase, tem estes hábitos, pois sua defesa antes da fala são suas ações como morder, unhar, bater. Esta situação é muito frequente com crianças nesta faixa etária, pois desta maneira explicaríamos para os responsáveis da criança, sempre tomando cuidado para não ofender os pais. (ESTUDANTE B-51)

Esse processo das crianças morderem faz parte do seu desenvolvimento, mas o professor pode fazer sua intervenção por meio do diálogo, conversar com a criança, explicar que morder o amiguinho dói e que isso não se faz e toda vez que acontecer conversar sempre e relatar à família, pedir para os pais também conversarem com seus filhos para aos poucos eles conseguirem internalizar que está errado morder o coleguinha. (ESTUDANTE B-60)

Entre os que participaram, 23 alunos não responderam à questão e um a relacionou com a falta de experiência, como podemos ver: "Não atuo em sala de berçário, logo não consigo falar sobre o assunto" (ESTUDANTE B-42). 
Nenhuma resposta envolveu a elaboração de um projeto educativo que tivesse como premissa partir dessa problemática: a mordida dos bebês. Enfim, propostas mais detalhadas que pudessem ocorrer em sala e que colaborassem na supressão desse comportamento. Ao analisarmos as respostas dadas, constatamos que, para o professor de formação inicial, não basta ter conhecimento do conteúdo para ensinar. Este elemento é imprescindível, mas são necessários conhecimentos para que os estudantes compreendam como ensinar de acordo com o contexto em que se ensina. Tais conhecimentos permitem a diminuição da fronteira que existe entre a formação inicial e a realidade escolar (VAILLANT; MARCELO, 2012).

Por último, perguntamos: "O que um professor de crianças de até um ano de idade deveria escrever num relatório de avaliação individual e quais os itens a serem contemplados a respeito da aprendizagem dos bebês". As respostas envolveram mais a construção da autonomia, desenvolvimento psicomotor e socialização, tal como podemos ver a seguir:

Motricidade; autonomia. (ESTUDANTE B-01)

Suas 'conquistas' e evoluções, a coordenação motora, seu movimento de 'pegar', 'puxar', sua curiosidade de exploração, são conquistas significativas que devem ser estimuladas. (ESTUDANTE B-09)

O professor irá avaliar o desenvolvimento do aluno, como se relaciona com os outros alunos, a coordenação motora, comportamento e afetividade. (ESTUDANTE B-18)

Contemplar se o bebê se adapta ou não à creche, se o bebê come bem ou não, se ele se socializa bem e se já está interagindo com os demais. (ESTUDANTE B-21)

De conter quais foram o desenvolvimento da criança. (ESTUDANTE B-36) Desenvolvimento pedagógico, autonomia, prévio desenvolvimento manual, percepção, etc. (ESTUDANTE B-42)

Outras respostas evidenciaram aspectos ligados à interação entre as crianças:

Interação e desenvolvimento. (ESTUDANTE B-10)

Interação com outras crianças, desenvolvimento motor, fala. (ESTUDANTE B-29)

Adaptação; relacionamento com os amigos, professores e funcionários. Comportamento, dificuldade na fala. (ESTUDANTE B-32)

A primeira palavra da criança, o seu desenvolvimento durante o período letivo, se a criança interagia com seus colegas de sala brincando. (ESTUDANTE B-39) 
Que desenvolveu a coordenação; relatar as atividades diárias da criança. (ESTUDANTE B-47)

Se já se alimenta com facilidade. Se interagem com o grupo. Se a criança se comunica ou tenta se comunicar. Se ela brinca com os amigos. (ESTUDANTE B-58)

A curiosidade, a interação com o meio, o tato e demais sentidos, envolvimento com os demais bebês. (ESTUDANTE B-59)

Dentre os participantes, 26 estudantes não responderam à questão. Apenas dois ressaltaram aspectos pedagógicos voltados às atividades planejadas pelo professor.

Seria interessante escrever o acompanhamento do desenvolvimento do bebê individualmente, desde seus movimentos, o que aprendeu a fazer, o que ainda não aprendeu a fazer (ex.: sentar, andar), explicando que cada criança alcança essas coisas em seu tempo. Falaria também sobre a linguagem, a fala, alimentação, interação do bebê com a turma e seu desenvolvimento com as brincadeiras e atividades. (ESTUDANTE B-26)

Mostrar o que foi trabalhado, ver os pontos positivos, se a oralidade da criança foi desenvolvida, se a criança sabe se expressar. (ESTUDANTE B38)

Partimos da concepção de Hoffmann (1999), quando diz que, na medida em que aumentam as discussões acerca da intencionalidade da educação infantil, também se ampliam as discussões a respeito da avaliação. O processo avaliativo "como base referencial dá-se abertura do professor ao entendimento das crianças com quem trabalha, pelo aprofundamento teórico que fundamenta a curiosidade sobre elas, pela postura mediadora (provocativa e desafiadora)" (p. 32). Sendo assim, o professor precisa de conhecimentos básicos ao propor desafios para que a criança avance na sua aprendizagem.

\section{Conclusão}

Repensar a formação dos professores de crianças pequenas para contribuir com a melhoria das práticas pedagógicas na educação infantil é compreender que os conteúdos específicos para crianças pequenas são importantes para que se desenvolva uma base de conhecimentos de conteúdos pedagógicos.

Para ensinar, o professor precisaria ter domínio do que ensina e possuir conhecimentos psicopedagógicos, que, por sua vez, contribuíssem para a construção de estratégias de ensino e avaliação. 
A docência na educação infantil precisaria também de algo específico, que valorizasse principalmente a brincadeira - pois esse conteúdo é a principal linguagem da criança com o mundo -, que oportunizasse experiências envolvendo a escrita e a matemática. Assim, desde bebê, essa criança estaria inserida no mundo científico, com investigação do seu meio. Mas, para isso, a proposta do curso de Pedagogia deveria partir da seguinte pergunta: "Qual professor este curso vai formar?".

Para Garcia (1999), a formação de professores é um processo contínuo que implica a integração entre a formação inicial e a formação permanente. A formação inicial não deveria ser vista como produto final, mas sim como o início de uma fase de um longo processo de desenvolvimento profissional. Sendo assim, pensamos que os professores iniciantes buscarão superar as lacunas da formação inicial no que se refere a ações pedagógicas com bebês e à construção da profissionalidade do professor de creche.

Resumidamente, concluímos:

- Ao analisar os nomes das disciplinas de ambos os cursos de Pedagogia, constatamos que, de um total de 41 disciplinas, apenas quatro têm o termo "educação infantil" em seu título. Cumpre lembrar que não encontramos a palavra "creche" compondo o título de nenhuma disciplina.

- Ao analisarmos as ementas, percebemos que o termo "creche" não foi citado em nenhuma disciplina. Já o termo "educação infantil” foi citado sete vezes. Vale ressaltar que o termo "educação infantil" engloba tanto creche quanto pré-escola. Além disso, vale mencionar também que não tivemos acesso às ementas da Universidade A.

- Os alunos da Universidade A vivenciaram o estágio na creche, mais do que os alunos Universidade B, que fizeram seus estágios prioritariamente na pré-escola e no ensino fundamental. Constatamos que o segmento da creche ficou em segundo plano. Esse aspecto deveria ser repensando no contexto da formação, pois o contato com este espaço educacional é um elemento importante na formação docente.

- Com a análise dos dados coletados por meio dos questionários, percebemos que há dois polos na compreensão da educação infantil: um vinculado ao cuidar e outro ao educar. Essa polarização é decorrência de marcas históricas que incidiram sobre o ambiente educativo. Nas falas das estudantes foi possível identificar que estamos num percurso que tenta superar essa polarização. Alunos de ambas as instituições lembraram que, na atuação do professor de educação, estão presentes aspectos pedagógicos e aqueles relacionados ao cuidar. 
- Os alunos de ambas instituições apontaram que o curso contribuiu para sua formação docente. Todavia, os alunos relatam que o curso é mais teórico do que prático e somente entram em contato com a prática por meio dos estágios.

- Quando indagados sobre quais conteúdos compõem a formação do profissional que atua em creche, foram mais evidenciados, nas respostas, blocos segmentados que envolviam: desenvolvimento da criança, afetividade, aspectos motores e brincadeiras. Apenas poucos alunos lembraram do desfralde como conteúdo que poderia estar presente no curso de Pedagogia.

- Os alunos, ao definirem o professor de creche, fizeram uso de muitos adjetivos: atencioso, comunicativo, expressivo, afetivo, zeloso, cuidadosos etc. Também fizeram referência a um profissional que é estimulador e que possui uma função vinculada tanto ao cuidar quanto ao educar. Percebemos uma preocupação em sair da visão de que o profissional que atua nesse segmento deveria ficar restrito às ações de cuidado da criança.

- Em ambas as instituições, oito alunos responderam que não possuíam determinados conhecimentos para responder às questões dissertativas, pois não atuavam na creche, ou seja, associavam que o conhecimento advém principalmente da prática.

- Algo preocupante foi o fato de alguns alunos compararem o papel de professor de educação infantil ao de um substituto da mãe/pai, como, por exemplo, na seguinte fala: "professor de creche, acima tudo tem que ter afeto, carinho, respeito, pois ali ele será como pai e mãe daqueles pequenos, paciente, compreensivo, é um educador e um cuidador ao mesmo tempo. Saber lidar com as famílias em sua diversidade, acolher sempre a criança, o carinho é essencial e isso sem pensar a qual família pertence, olhar a criança em suas particularidades e individualidades" (ESTUDANTE A-38).

Finalizando, evidenciamos a ideia da formação inicial que atuará em creche em propiciar ao aluno de Pedagogia o desenvolvimento de uma atitude investigativa e o compromisso com a educação da criança pequena.

\section{REFERÊNCIAS}

BRASIL. Constituição da República Federativa do Brasil de 1988. Disponível em: http://www.planalto.gov.br/ccivil_03/constituicao/constituicaocompilado.htm. Acesso: 18 jul. 2016. 
BRASIL. Lei de Diretrizes e Bases da Educação Nacional - LDB. Lei nº 9394 de 20 de dezembro de 1996. Estabelece as diretrizes e bases da educação nacional. Disponível em: http://www.mec.gov.br/legislações/ldb. Acesso: 25 abr. 2015.

BRASIL. Referenciais Curriculares de Educação Infantil. Brasília: MEC/SEF, 1998.

BRASIL. Diretrizes Curriculares Nacionais para a formação inicial em Nível Superior. Resolução $n^{\circ}$ 2, de $1^{\text {o }}$ de julho de 2015. Brasília: MEC/CNE, 2015. Disponível: http://portal.mec.gov.br/docman/agosto-2017-pdf/70431-res-cne-cp-002-03072015-pdf/file. Acesso: 26 ago. 2019.

BRASIL. Ministério da Educação/INEP. Resultados finais de censo escolar. 2014. Disponível em: http://portal.inep.gov.br/basica-censo. Acesso: 27 mai. 2016.

FORMOSINHO, J.O. O desenvolvimento profissional das professoras de educação infantil. In: MACHADO, M.L.A. Encontros e desencontros em Educação Infantil. São Paulo: Cortez, 2005.

FREIRE, P. Pedagogia da autonomia: saberes necessários à prática educativa. São Paulo; Paz e terra, 1996.

IMBERNÓN, F. Formação docente e profissional: formar-se para a mudança e incerteza. São Paulo: Cortez, 2002.

GARCIA, C. M. Formação de professores: para uma mudança educativa. Porto, Pt: Porto Editora, 1999.

HOFFMANN, J. Avaliação mito \& desafio: uma perspectiva construtivista. $26^{\text {a }}$ ed. Porto Alegre: Mediação, 1999.

KRAMER, S. Formação de profissionais da educação infantil: questões e tensões. In: MACHADO, M.L.A. Encontros e desencontros em Educação Infantil. São Paulo: Cortez, 2005.

KRAMER, S. Direitos da criança e projeto político pedagógico na Educação Infantil. In: BASILIO, L. C.; KRAMER, S. Infância, Educação e Direitos humanos. São Paulo, Cortez, 2006.

KUHLMANN, J. M. Instituições Pré-Escolares Assistencialista no Brasil (1889-1922).

Cadernos de Pesquisas. São Paulo, n.78, p.18-21, ago.1991. Disponível em:

http://publicacoes.fcc.org.br/ojs/index.php/cp/article/view/1027 Acesso: 18 jul. 2016.

KUHLMANN, J. M. História da educação infantil brasileira. Revista brasileira de educação. São Paulo, No 14, p. 5-14, 2000. Disponível em:

http://www.scielo.br/pdf/rbedu/n14/n14a02.pdf. Acesso: $18 \mathrm{dez} 2016$

MIZUKAMI, M.G.N. Ensino: as abordagens do processo. São Paulo: EPU, 1986.

OLIVEIRA, Z. M. Educação Infantil: Fundamentos e Métodos. São Paulo: Cortez, 2011. 
RIZZINI, I. Meninos Desvalidos e menores Transviados: A trajetória da Assistência pública até a Era Vargas. In: PILOTTI, F. RIZZINI, I. org. A arte de governar crianças: a história das políticas sociais, da legislação e da assistência a infância no Brasil. Rio de Janeiro: Instituto Interamericano Del Niño, Editora Santa Úrsula, Amais Livraria e editora, 1995.

ROCHA, H. H. P. A higienização da infância no “século da criança”. In: FARIA, A. L. G. Linguagens Infantis. Campinas, São Paulo: Autores Associados, 2005.

SÃO PAULO. Creche - Programação Básica. Coordenadoria do Bem-estar social. Assessoria de orientação técnica e programas. São Paulo, 1981.

SHULMAN, L. S. Conhecimento e ensino: Fundamentos para a nova reforma. 1987. Cadernos Cenpec, São Paulo, v.4, n², p.196-229, 2014. Disponível em: http://cadernos.cenpec.org.br/cadernos/index.php/cadernos/article/view/293. Acesso: 18 dez. 2016.

TANURI, L. M. História da formação de professores. Revista Brasileira de Educação, Mai/Jun/Jul/Ago, 2000, No 14. Disponível em:

http://www.scielo.br/pdf/rbedu/n14/n14a05.pdf. Acesso: 23 out. 2016.

VAILLANT, D.; MARCELO, C. A Formação inicial docente. In: VAILLANT, D.

MARCELO, C. Ensinando a ensinar: as quatro etapas de uma aprendizagem. Curitiba: Ed. UTFPR, 2012.

VIEIRA, L. M. F. Mal necessário: creches no departamento nacional da criança (1940-1970). Cadernos de Pesquisa. São Paulo, p.3-16, nov.1988. Disponível em:

http://www.fcc.org.br/pesquisa/publicacoes/cp/arquivos/830.pdf Acesso: 27 mai. 2016.

\section{$\underline{\text { SOBRE AS AUTORAS }}$}

\section{Lilian de Assis Monteiro Lizardo}

Doutoranda em Educação: Currículo pela Pontifícia Universidade Católica (PUC/SP). Docente na Prefeitura do Município de São Paulo. Bolsista CAPES. E-mail: proflilianmonteiro@gmail.com

iD http://orcid.org/0000-0001-7832-832X

\section{Maria de Fátima Ramos de Andrade}

Doutora em Comunicação Semiótica pela Pontifícia Universidade Católica (PUC/SP). Docente na Universidade Presbiteriana Mackenzie; Programa de Stricto Sensu em Educação. E-mail: mfrda@uol.com.br

(iD https://orcid.org/0000-0003-4945-8752 